\title{
Evaluation of the Healing of Meshed Skin Auto Grafts of 1:3 Meshing Size Covered by Fresh Amniotic Membrane Dressings: A Prospective Multicenter Study
}

\author{
MOHAMED SABRY, M.B.B.Ch.*; AHMED EL-SHERIF, M.D.**; ADEL HUSSIEN AMR, M.D.**; \\ HEBA MOHAMED TAWFIK, M.D.***; ABDOU MOHAMED ABDALLAH DARWISH, M.D.* and \\ AHMED EL-SHAHAT, M.D.**
}

The Department of Plastic and Reconstructive Surgery, Minia University Hospital, Minia*, Ain Shams University Hospital, Cairo** and the Department of Pathology, Faculty of Medicine, Minia University, Minia***, Egypt

\begin{abstract}
Background: Since the development of the meshed skin grafts and the availability of different meshing expansion sizes, the sizes of the meshed skin grafts interstices like all open wounds became a problem because they increase the metabolic needs and put the patients at the risk of infection. The amniotic membrane satisfies most of the criteria for an ideal biological wound dressing to solve such a problem.
\end{abstract}

Aim of Study: To determine the rate of healing of the interstices of meshed skin autograft of 1:3 meshing size applied to post burn raw areas when covered by fresh amniotic membranes.

Patients and Methods: This study was conducted on 30 patients who had post burn raw areas with TBSA less than $30 \%$ divided into 2 groups Group (1): Used meshed STSG (1:3) without amniotic membrane coverage Group (2): Used meshed STSG 1:3 then covered with fresh amniotic membrane. Biopsies were taken and examined. Patient and Observer Scar Assessment Scale (POSAS) was used to evaluate the aesthetic out come.

Results: Amniotic Membrane (AM) did not improve skin graft take but it improved the macroscopic healing of the interstices which showed significant $p$-value $0.005^{*}$ and registered valuable decrease in all items of Patient and Observer Scar Assessment Scale (POSAS) that showed significant $p$ values.

Also, AM accelerated the healing process histologically: The chronic inflammatory cells started to appear early ( $p$ value: $\left.0.003^{*}\right)$. In the $10^{\text {th }}$ day both the maturation of the epithelium and the transformation of newly formed capillaries into mature ones showed $p$-values $\left(0.006^{*}\right)$.

Conclusion: Amniotic membrane enhanced maturation of epithelium, increased the transformation of the newly formed capillaries into mature ones, accelerated the initiation of the proliferative phase of wound healing, promoted the reepithelialization of the interstices of the meshed graft and led to a better cosmetic outcome.

Key Words: Burn - Amniotic membrane-Meshed skin graft.

\section{INTRODUCTION}

Meshed split thickness skin autograft, especially when needed to be widely expanded in cases of patients with burned large total body surface areas; this puts patients at risk of exposure to multiple metabolic problems and life threatening infections. To control these risks in the open skin autografts interstices, a sandwich technique with an allograft overlay has been introduced [1,2]. Each gap on the meshed graft could be considered an individual wound and has to heal by secondary intention. Therefore, the wider is the mesh the more it is liable to heal by secondary intention and scarring $[3,4]$.

Amniotic Membrane (AM) is a biomaterial for various purposes in reconstructive surgery and wound-healing research since its initial description as a transplantable material by Davis in 1910 [5]. $\mathrm{AM}$ is used in burn wounds, with efficiency of maintaining low bacterial counts, reducing loss of protein, electrolytes and fluids, minimizing pain, accelerating wound healing and reducing scar tissue formation. In addition it is readily available, easily applicable and economic [6-9].

\section{Aim of work:}

The aim of this study is to determine the rate of healing of the interstices of meshed skin autograft of 1:3 meshing size applied to excised post burn raw areas when covered by fresh amniotic membranes. Histological examination will determine the features of the tissues that filled the gaps (interstices) of meshed skin autografts. Patient and 
Observer Scar Assessment Scale (POSAS) was used to evaluate the aesthetic out come.

\section{PATIENTS AND METHODS}

Between October 2015 and March 2018, in a prospective experimental, multicenter and clinical study on 30 patients in both Ain Shams and Minia Universities Burn Units.

The patients included in this study, have second_ and third_degree burns raw areas with Total Body Surface Areas (TBSA) less than 30\%.

All patients needed meshed split-thickness skin graft. We did not use the technique of acute early excision and grafting $(\mathrm{E} \& \mathrm{G})$.

Our exclusion criteria were age more than 60 and less than 5, facial burns, burns of the hands, serum albumin level less than 2.5 , hemoglobin less than 10 gram percent, history of cardiovascular disease, renal failure, diabetes mellitus, corticosteroid therapy and any other metabolic disorder. Patients who died during their management were also excluded.

We received the approval of local ethics committees (Ain Shams University, Faculty of Medicine, Research Ethics Committee (REC) FWA 000017585) and the patients or their guardians provided informed consent.

Patients were divided into three main groups:

- Group (1): 15 patients treated by meshed split thickness skin graft (1:3) without amniotic membrane coverage as a control group.

- Group (2): 15 patients treated by meshed split thickness skin graft 1:3 then covered with fresh amniotic membrane.

\section{Collection of amniotic membrane:}

The amniotic membranes were obtained from placenta during elective caesarean sections of mothers without sexually transmitted disease, endometritis, and premature rupture membranes, and with negative HIV, HCV, HBS, AIDS and CMV tests. After washing with normal saline, the separated amniotic membranes from placenta, were placed in a pot contain normal saline and $80 \mathrm{mg} / \mathrm{L}$ gentamicin, and stored in refrigerator at $4^{\circ} \mathrm{C}[10]$. The AM was applied after 2-3 days of its harvesting.

\section{Surgical procedure:}

In the context of reconstructive procedures, a standardized STSG of (0.014 inch) thickness harvested by electric dermatome (Zimmer® Electric
Dermatome) printed in USA 1992, 1996 ZIMMER.INC REF.8821-01 then meshed by (Zimmer® Skin Graft Mesher) Meshgraft ${ }^{\mathrm{TM}}$ II System printed in USA ZIMMER.INC REF 2195-01 serial no 16145 using 1:3 through the use of the Dermacarriers $^{\mathrm{TM}}$ II Skin Graft Carriers.

After tangential excision of the necrotic and eschar tissue, autografts were placed on the burn wound area. The procedure was performed on a mean of 16 days from the initial injury. During this time the patients received the burn formula, repeated tangential excision of the burn eschar, repeated dressings by b-sitosterol containing ointment and culture and sensitivity was performed if any sign of infection and the sensitive antibiotic was given.

The graft was spread to the maximum degree possible to maximize the extent of the graft interstices. In group 1 the (control group) no amniotic membrane coverage used for the meshed skin graft. In group 2; the maximally spread meshed graft sandwiched with a layer of AM (the mesenchymal surface touched the graft) and the AM is fixed by skin staples at its edges (because of its slippery property). Then AM was covered with Vaseline gauzes and then dry gauzes as a dressing. In the (control group) after debridement and skin grafting, Vaseline gauzes and then dry gauzes were used as dressing.

\section{Evaluation of the wound healing process:}

The wound healing process evaluated on postoperative days $5,7,10$ and 30 by photo documentation with an 8 MP Samsung mobile camera and standardized with incisional biopsies taken from the interstices (opening windows) of the meshed STSG to assess the type of tissues formed. The entire dressing was changed at the time of the biopsy and the photography was taken.

If the AM still present or dry must be left in place but if dissolved should be replaced by another one that is prepared before dressing. The only indication for removal of the AM is infection.

The success rate of graft take was compared between two groups by the same surgeon using the formula:

Graft takes surface area $\left(\mathrm{cm}^{2}\right) \times 100 \%$ :

Total grafted area $\left(\mathrm{cm}^{2}\right)$.

- Samples investigated histologically by hematoxylin and eosin (H \& E) staining for the maturation of the epithelial layer, collagen ,granulation tissue, 
type of inflammatory cells and type of blood vessels formed.

- Olympus microscope (made in Japan model no bx50f4) was used to examine and document photos of the specimens. The percentage of the take of the graft was documented and compared among the groups. The date of macroscopic interstices complete healing was documented.

- At the $30^{\text {th }}$ day the end result of these procedures was evaluated by POSAS [19] (patient and observer scar assessment scale) to evaluate the formed tissues to avoid any bias (after the $30^{\text {th }}$ day many patient started anti-scar measures (pressure garments and anti-scar creams) in order to improve their outcomes).

- Collected data were presented as mean and standard deviation (mean \pm S.D.). Statistical comparisons between groups were carried out by using SPSS 24.0 software. One-way ANOVA test with post hoc Tukey used for analysis of quantitative data between groups and Chi square test for analysis of qualitative data between groups. Significant difference at $p<0.05$.

\section{RESULTS}

The study was performed on patients had post burn areas who were 30 patients and fulfilled the entry criteria. Their mean age was (5-35) $14.73 \pm$ 10.014. $17(56.7 \%)$ were males and $13(43.3 \%)$ were females. The cause of burn was flame burn in $10(33.3 \%)$ inpatients and scald burn was the cause in $20(66.7 \%)$ of patients. The total body surface area ranged TBSA (5-15\%) 8.83 \pm 4.178 .

The time of macroscopic healing of the interstices after the surgical procedure in days ranged with mean \pm SD (7-12) 9.3 \pm 1.5 days and (7-10) $7.7 \pm 1.2$ in group 1 and 2 respectively which showed significant $p$-value $0.005^{*}$ when group 1 compared vs. 2.

The take of the grafts as a percentage did not show any significant $p$-values as the take in group 1 ranged with mean \pm SD (60-98\%) $81.5 \pm 17$ and in group 2 (70-100\%) $90.5 \pm 10.2$.

The results provided by PSAS see (Table 1 ) showed a substantial decrease in AM groups (2) of the scores of the whole items; (pain, itching, color, stiffness, scar thickness, scar irregularities, total patient and overall opinion) with significant p-values: $\left(<0.001^{*}, 0.003^{*}, 0.004^{*}, 0.003^{*}\right.$, $<0.001^{*}, 0.001^{*}, 0.001^{*}$ and $\left.<0.001^{*}\right)$ respectively.
Also in the group (2), all items of OSAS see (Table 2 ) showed a statically significant ( $p$-value: $<0.001^{*},<0.001^{*}, 0.018^{*}, 0.019^{*}, 0.002^{*}, 0.002^{*}$, $0.002 *$ and $0.003 *)$ when all the items of PSAS (vascularity, pigmentation, thickness, relief, pliability, surface area, total observer and overall observer opinion) were compared respectively in group 1 vs. 2.

The granulation tissue was present between the interstices of the meshed STSGs in both groups at the $5^{\text {th }}$ day. In the $7^{\text {th }}$ day the granulation tissue disappeared in $6(40 \%)$ of patients in group with an observed decrease of the presence of granulation tissue in the interstices in $13(86.7 \%)$ of patients in group 2 with a significant $p$-value: $0.008^{*}$ when comparing group 1 vs. 2 . That is clinically correlated to the role of AM in rapid epithelization and resurfacing the interstices with epithelium which decrease the incidence of overgrowth granulation tissue.

Inflammatory cells (predominantly the acute type) in the $5^{\text {th }}$ day had the major representation in all groups. The chronic type of the inflammatory cells (mainly fibroblasts) started to appear in group (2) with the use of AM coverage in the $5^{\text {th }}$ day in $8(53.3 \%)$ of the specimens with a statistically significant $p$-value: $0.003^{*}$ when comparing group 1 vs. 2 . The early appearance of fibroblasts in the AM group accelerates the beginning of the proliferative phase and deposit new extracellular matrix. The new collagen matrix then becomes crosslinked and organized during the final remodeling phase.

The collagen started to appear as fibrils in all the specimens in all groups in the $5^{\text {th }}$ day then collagen is transferred and arranged into bundles in the $7^{\text {th }}$ day with no significant $p$-values.

In the $10^{\text {th }}$ day the maturation of the epithelium was noticed in all biopsies $15(100 \%)$ of group 2 with a significantly $p$-value: $0.006^{*}$ when the control group 1 compared with group 2 . That registered the ability of AM in early production of keratinized stratified squamous epithelium that correlates to a stable coverage.

The newly formed capillaries (immature ones) were prevailing in all biopsies of all groups in the $5^{\text {th }}$ day. In the $10^{\text {th }}$ day the mature blood vessels overwhelmed all the biopsies of group (2) with the use of AM coverage with a statically significant $p$-values $\left(0.006^{*}\right)$ when comparing group 1 vs. 2 . 
Table (1): Results of observer scar assessment scale (PSAS).

\begin{tabular}{|c|c|c|c|}
\hline Patient & $\begin{array}{l}\text { Group I } \\
\mathrm{N}=15\end{array}$ & $\begin{array}{c}\text { Group II } \\
\mathrm{N}=15\end{array}$ & $\begin{array}{c}p- \\
\text { value }\end{array}$ \\
\hline \multicolumn{4}{|l|}{ Painful: } \\
\hline Range & $(2-7)$ & $(1-4)$ & $<0.001 *$ \\
\hline Mean \pm SD & $4.1 \pm 1.5$ & $2.1 \pm 1$ & \\
\hline \multicolumn{4}{|l|}{ Itching: } \\
\hline Range & $(2-7)$ & $(1-4)$ & $0.003^{*}$ \\
\hline Mean \pm SD & $4.5 \pm 1.9$ & $2.6 \pm 1.2$ & \\
\hline \multicolumn{4}{|l|}{ Color: } \\
\hline Range & $(2-7)$ & $(1-4)$ & $0.004^{*}$ \\
\hline Mean \pm SD & $4.3 \pm 1.9$ & $2.5 \pm 1.1$ & \\
\hline \multicolumn{4}{|l|}{ Stiffness: } \\
\hline Range & $(2-7)$ & $(1-4)$ & $0.003^{*}$ \\
\hline Mean \pm SD & $4.6 \pm 1.9$ & $2.7 \pm 1.2$ & \\
\hline \multicolumn{4}{|l|}{ Scar thickness: } \\
\hline Range & $(3-7)$ & $(1-4)$ & $<0.001 *$ \\
\hline Mean \pm SD & $4.6 \pm 1.6$ & $2.5 \pm 1.1$ & \\
\hline \multicolumn{4}{|c|}{ Scar irregularity: } \\
\hline Range & $(2-7)$ & $(1-4)$ & $0.001 *$ \\
\hline Mean \pm SD & $4.5 \pm 1.8$ & $2.3 \pm 1$ & \\
\hline \multicolumn{4}{|l|}{ Total patient: } \\
\hline Range & $(14-42)$ & $(6-22)$ & $0.001 *$ \\
\hline Mean \pm SD & $26.5 \pm 10.4$ & $14.7 \pm 5.8$ & \\
\hline \multicolumn{4}{|c|}{ Overall opinion: } \\
\hline Range & $(3-6)$ & $(2-4)$ & $<0.001 *$ \\
\hline Mean \pm SD & $4.4 \pm 1.2$ & $2.8 \pm 0.8$ & \\
\hline
\end{tabular}

Table (3): Results of maturation of epithelium.

\begin{tabular}{|c|c|c|c|}
\hline Epithelium & $\begin{array}{c}\text { Group I } \\
\mathrm{N}=15\end{array}$ & $\begin{array}{c}\text { Group II } \\
\mathrm{N}=15\end{array}$ & $\begin{array}{c}p- \\
\text { value }\end{array}$ \\
\hline \multicolumn{4}{|l|}{ At $5^{\text {th }}:$} \\
\hline No & $14(93.3 \%)$ & $15(100 \%)$ & \multirow[t]{3}{*}{0.309} \\
\hline Immature & $1 \quad(6.7 \%)$ & $0 \quad(0 \%)$ & \\
\hline Mature & $0 \quad(0 \%)$ & $0 \quad(0 \%)$ & \\
\hline \multicolumn{4}{|l|}{ At $7^{\text {th }}$} \\
\hline No & $4(26.7 \%)$ & $2(13.3 \%)$ & \multirow[t]{3}{*}{0.512} \\
\hline Immature & $4(26.7 \%)$ & $3 \quad(20 \%)$ & \\
\hline Mature & $7(46.7 \%)$ & $10(66.7 \%)$ & \\
\hline \multicolumn{4}{|l|}{ At $10^{\text {th }}$ : } \\
\hline No & $0(0 \%)$ & $0 \quad(0 \%)$ & \multirow[t]{3}{*}{$0.006 *$} \\
\hline Immature & $6(40 \%)$ & $0 \quad(0 \%)$ & \\
\hline Mature & $9(60 \%)$ & $15(100 \%)$ & \\
\hline \multicolumn{4}{|l|}{ At $30^{\text {th }}$ : } \\
\hline No & $0 \quad(0 \%)$ & $0 \quad(0 \%)$ & \multirow[t]{3}{*}{-} \\
\hline Immature & $0 \quad(0 \%)$ & $0 \quad(0 \%)$ & \\
\hline Mature & $15(100 \%)$ & $15(100 \%)$ & \\
\hline \multicolumn{4}{|l|}{ p-value: } \\
\hline $5^{\text {th }}$ vs. $7^{\text {th }}$ & $0.003^{*}$ & $0.001 *$ & \\
\hline $5^{\text {th }}$ vs. $10^{\text {th }}$ & $<0.001 *$ & $<0.001 *$ & \\
\hline $5^{\text {th }}$ vs. $30^{\text {th }}$ & $<0.001 *$ & $<0.001 *$ & \\
\hline
\end{tabular}

Table (2): Results of patient scar assessment scale (OSAS)

\begin{tabular}{|c|c|c|c|}
\hline Observer & $\begin{array}{c}\text { Group I } \\
\mathrm{N}=15\end{array}$ & $\begin{array}{c}\text { Group II } \\
\mathrm{N}=15\end{array}$ & $\begin{array}{c}p- \\
\text { value }\end{array}$ \\
\hline \multicolumn{4}{|l|}{ Vascularity: } \\
\hline Range & $(2-7)$ & $(1-3)$ & $0.001 *$ \\
\hline Mean \pm SD & $4.1 \pm 1.8$ & $2.2 \pm 0.9$ & \\
\hline \multicolumn{4}{|l|}{ Pigmentation: } \\
\hline Range & $(2-7)$ & $(1-3)$ & $<0.001 *$ \\
\hline Mean \pm SD & $4.6 \pm 1.9$ & $2.3 \pm 0.9$ & \\
\hline \multicolumn{4}{|l|}{ Thickness: } \\
\hline Range & $(2-7)$ & $(1-4)$ & $0.018^{*}$ \\
\hline Mean \pm SD & $3.9 \pm 1.8$ & $2.5 \pm 1.1$ & \\
\hline \multicolumn{4}{|l|}{ Relief: } \\
\hline Range & $(2-8)$ & $(1-4)$ & $0.019 *$ \\
\hline Mean \pm SD & $4.3 \pm 2.3$ & $2.6 \pm 1.2$ & \\
\hline \multicolumn{4}{|l|}{ Pliability: } \\
\hline Range & $(2-8)$ & $(1-4)$ & $0.002 *$ \\
\hline Mean \pm SD & $4.7 \pm 1.9$ & $2.7 \pm 1.2$ & \\
\hline \multicolumn{4}{|l|}{ Surface area: } \\
\hline Range & $(3-8)$ & $(1-4)$ & $0.002 *$ \\
\hline Mean \pm SD & $4.8 \pm 1.7$ & $2.9 \pm 1.2$ & \\
\hline \multicolumn{4}{|l|}{ Total observer: } \\
\hline Range & $(14-45)$ & $(6-22)$ & $0.002 *$ \\
\hline Mean \pm SD & $26.3 \pm 11.1$ & $15.1 \pm 6.1$ & \\
\hline \multicolumn{4}{|c|}{ Overall opinion: } \\
\hline Range & $(2-6)$ & $(2-4)$ & $0.003 *$ \\
\hline Mean \pm SD & $4.3 \pm 1.2$ & $3 \pm 0.8$ & \\
\hline
\end{tabular}

Table (4): Results of transformation of immature blood vessels into mature ones.

\begin{tabular}{|c|c|c|c|}
\hline Blood vessels & $\begin{array}{c}\text { Group I } \\
\mathrm{N}=15\end{array}$ & $\begin{array}{c}\text { Group II } \\
\mathrm{N}=15\end{array}$ & $\begin{array}{c}p- \\
\text { value }\end{array}$ \\
\hline \multicolumn{4}{|l|}{ At $5^{\text {th }}$} \\
\hline Immature & $15(100 \%)$ & $15(100 \%)$ & \multirow[t]{3}{*}{-} \\
\hline Mature & $0 \quad(0 \%)$ & $0 \quad(0 \%)$ & \\
\hline Mixed & $0 \quad(0 \%)$ & $0 \quad(0 \%)$ & \\
\hline \multicolumn{4}{|l|}{ At $7^{\text {th }}$} \\
\hline Immature & $1 \quad(6.7 \%)$ & $0 \quad(0 \%)$ & \multirow[t]{3}{*}{0.309} \\
\hline Mature & $14(93.3 \%)$ & $15(100 \%)$ & \\
\hline Mixed & $0 \quad(0 \%)$ & $0 \quad(0 \%)$ & \\
\hline \multicolumn{4}{|l|}{ At $10^{\text {th }}$} \\
\hline Immature & $6(40 \%)$ & $0 \quad(0 \%)$ & \multirow[t]{3}{*}{$0.006^{*}$} \\
\hline Mature & $9(60 \%)$ & $15(100 \%)$ & \\
\hline Mixed & $0(0 \%)$ & $0 \quad(0 \%)$ & \\
\hline \multicolumn{4}{|l|}{ At $30^{\text {th }}$} \\
\hline Immature & $0 \quad(0 \%)$ & $0 \quad(0 \%)$ & \multirow[t]{3}{*}{-} \\
\hline Mature & $15(100 \%)$ & $15(100 \%)$ & \\
\hline Mixed & $0 \quad(0 \%)$ & $0 \quad(0 \%)$ & \\
\hline \multicolumn{4}{|l|}{ p-value: } \\
\hline $5^{\text {th }}$ vs. $7^{\text {th }}$ & $<0.001 *$ & $<0.001 *$ & \\
\hline $5^{\text {th }}$ vs. $10^{\text {th }}$ & $0.003 *$ & $<0.001 *$ & \\
\hline $5^{\text {th }}$ vs. $30^{\text {th }}$ & $<0.001 *$ & $<0.001 *$ & \\
\hline
\end{tabular}



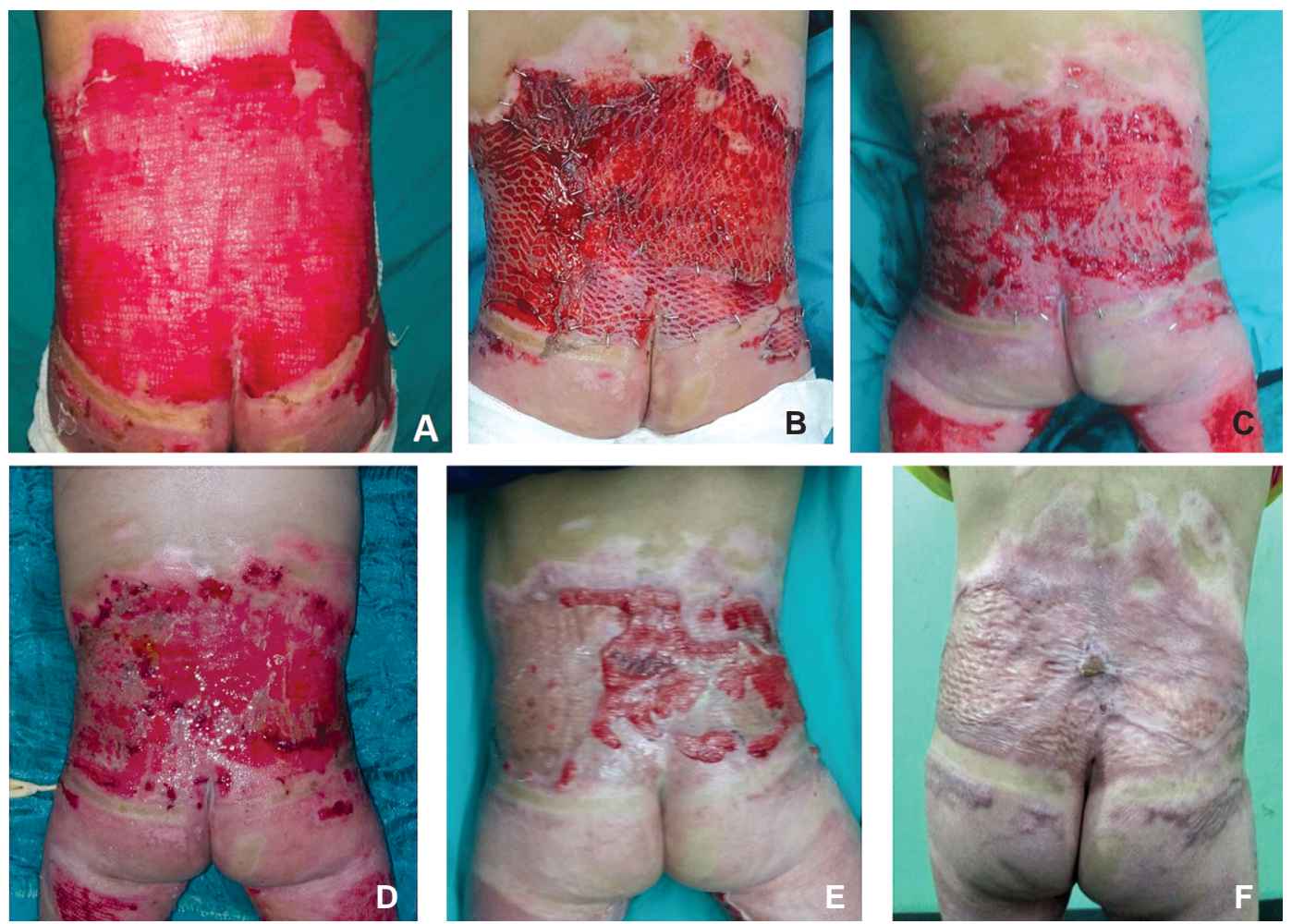

Fig. (1): Group 1 male patient 5 years old with post burn raw area on the back (A) then treated with meshed STSG of 1:3 expansion ratio (B), (C) the first dressing in the $5^{\text {th }}$ day showing partial loss of the graft, (D) in the $7^{\text {th }}$ day, (E) in the $10^{\text {th }}$ day with a resultant raw area which needed another operation and $(\mathrm{F})$ showing the end result after the $2^{\text {nd }}$ operation.
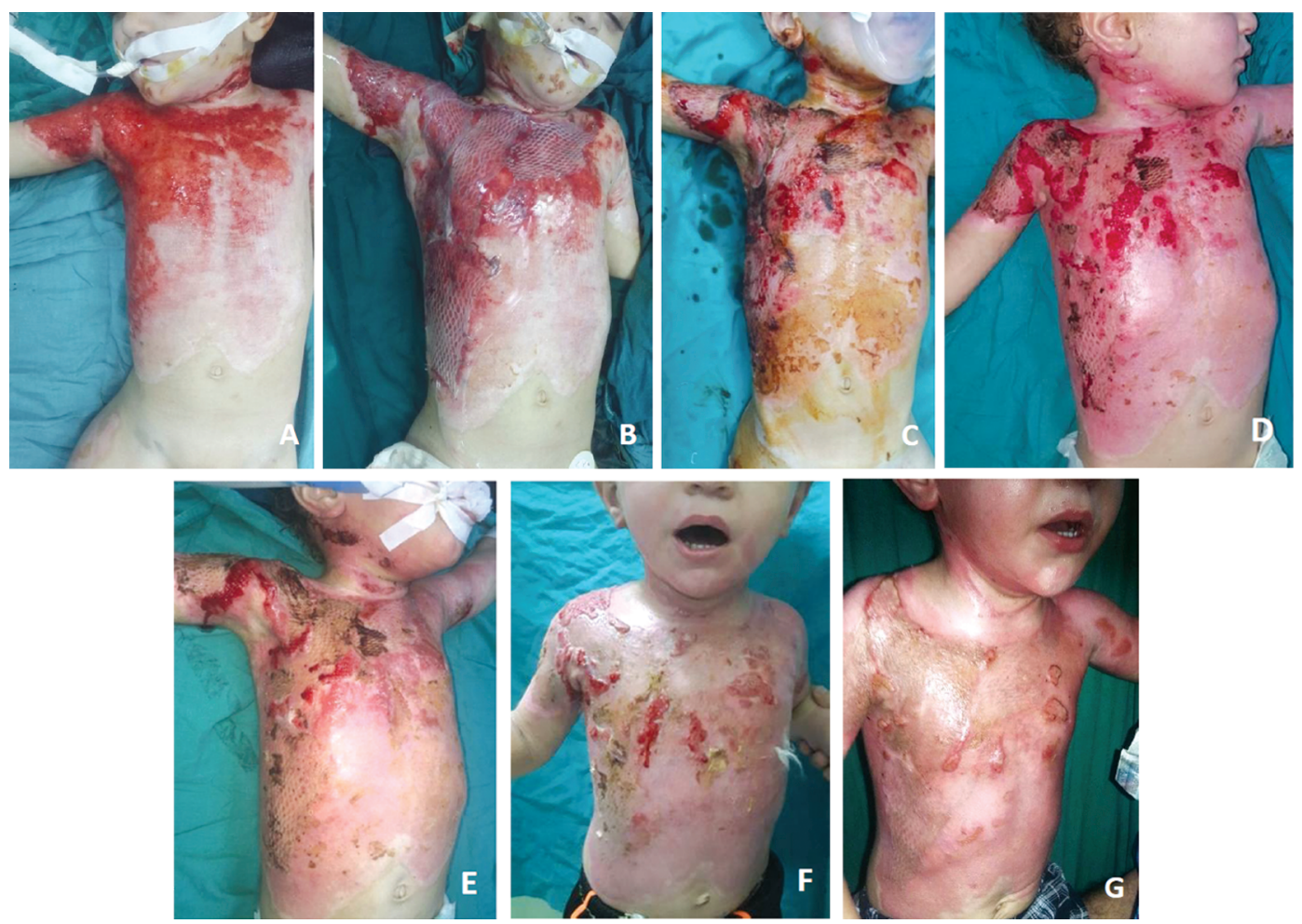

Fig. (2): Group 2 male patient 5 years old with post burn raw area on the ant chest, abdomen and it upper limb (A) then treated with meshed STSG of 1:3 expansion (B), AM covering the meshed STSG $(C, D)$ a the first dressing in the $5^{\text {th }}$ day (D) in the $7^{\text {th }}$ day with complete healing, (F) at the $10^{\text {th }}$ (G) at $30^{\text {th }}$ day post operative. 

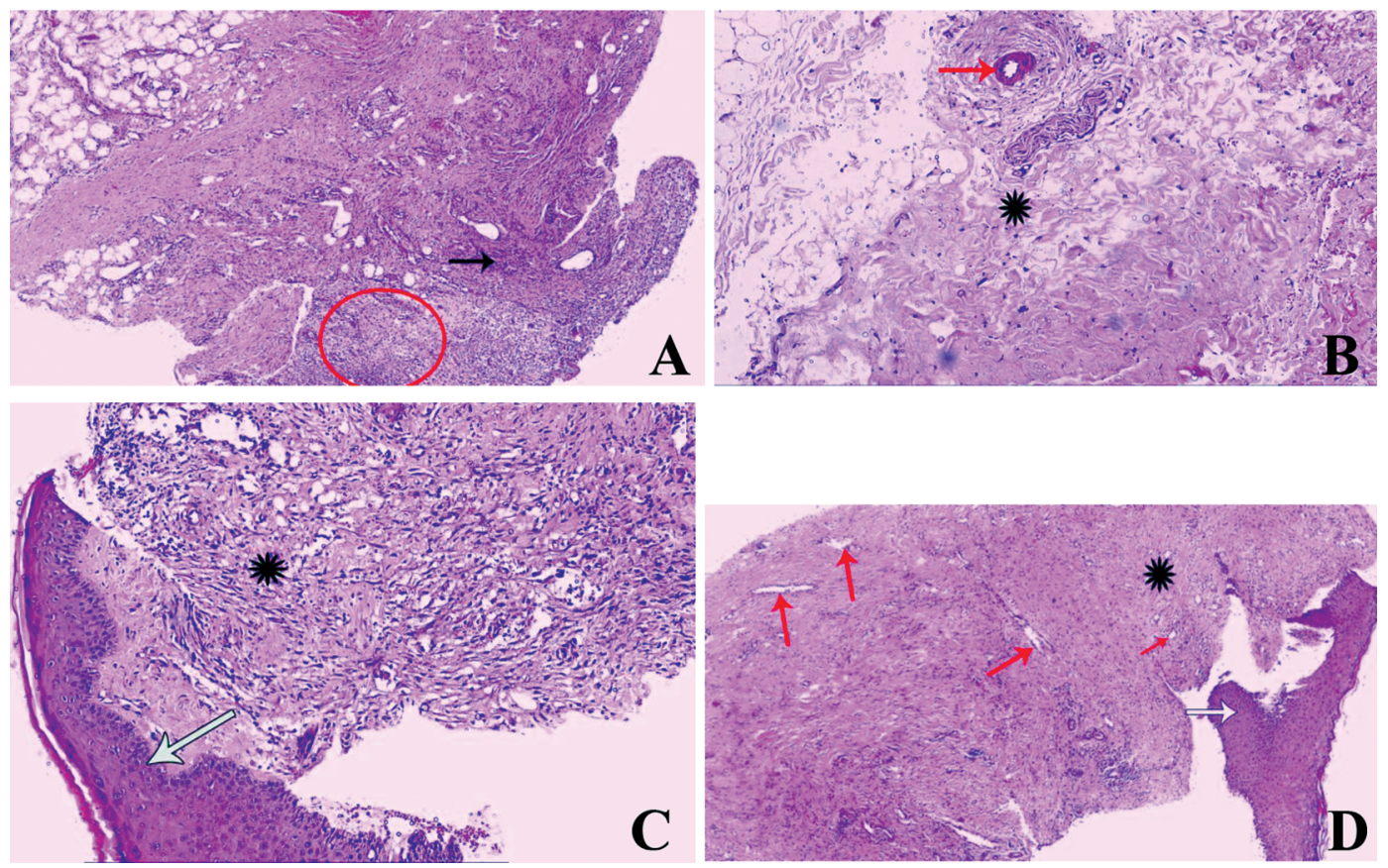

Fig. (3): Control group showing (A) granulation tissue at the $5^{\text {th }}$ day consisting inflammatory cells mostly acute red circle and newly formed capillaries black arrows. (B) Still granulation tissue at the $7^{\text {th }}$ day but contains mature blood vessels red arrows and collagen bundles black star. (C) The $10^{\text {th }}$ day shows mature epithelium white arrow, collagen bundles black star. (D) The $30^{\text {th }}$ days shows collagen bundles black star and mature blood vessels red arrows. Mature epithelium white arrow.
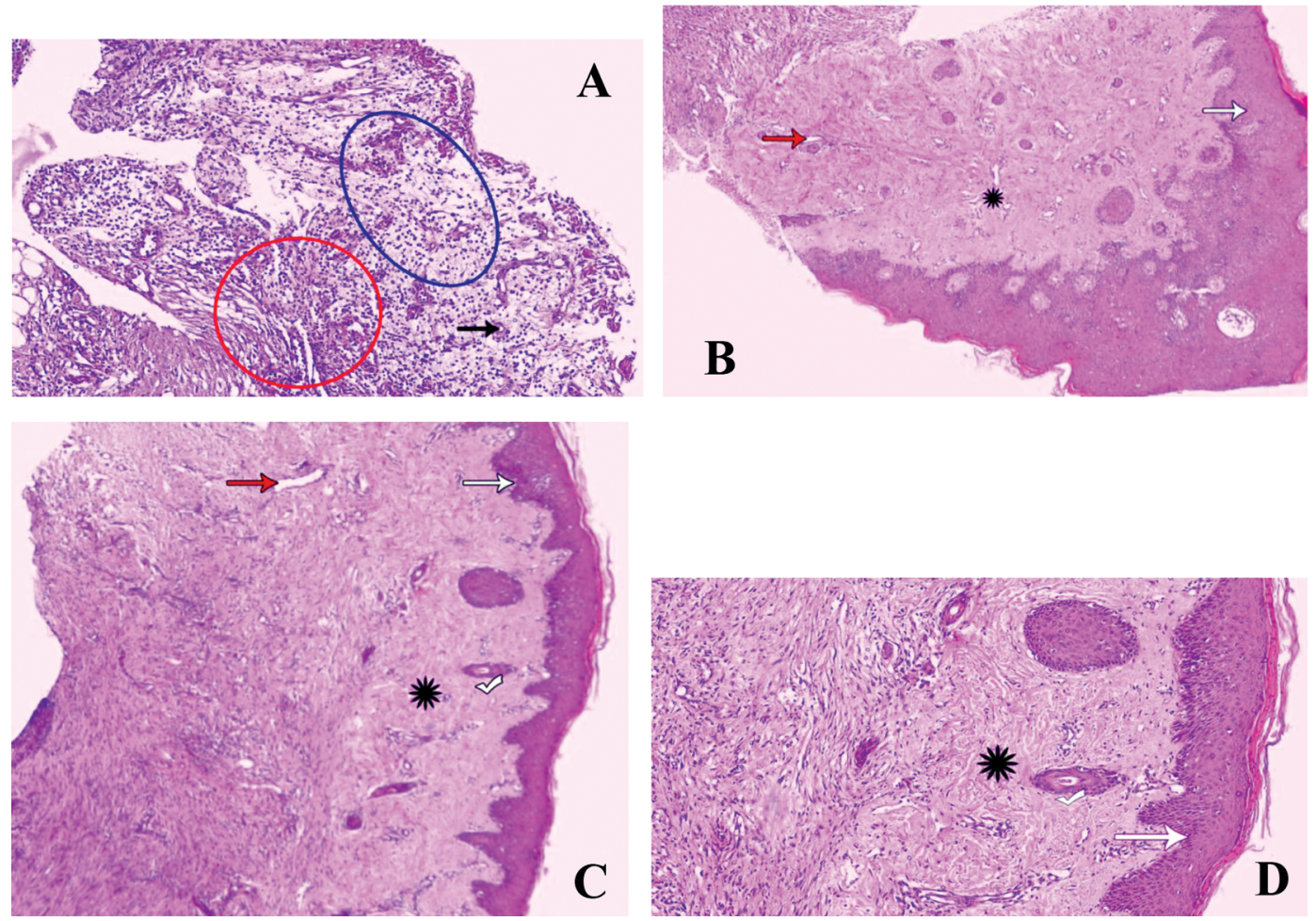

Fig. (4): Group 2 showing (A) the $5^{\text {th }}$ day granulation tissue contains oedema blue circle, acute inflammatory cells red circle and newly formed capillaries black arrow. (B) The $7^{\text {th }}$ day shows collagen bundles black star, mature epithelium white arrow and mature blood vessels red arrow. (C) The $10^{\text {th }}$ day shows mature epithelium white arrow, collagen bundles black star and mature blood vessel red arrow and hair follicle white right mark. (D) The $30^{\text {th }}$ days shows collagen bundles black star, mature epithelium white arrow and hair follicle white right mark. 


\section{DISCUSSION}

With the development of the expanded skin by Tanner et al., [11] and the availability of different meshing expiation sizes. The sizes of the open areas of the meshed skin grafts interstices are similar to all open wounds increase the metabolic needs of these patients and put them at the risk of bacterial invasion [12].

In the present study the AM used in group (2) reported no antigenicity or needed immunosuppressive drugs in agreement with the study of Lin et al., [13].

Lin et al., [13] used fresh AM for coverage for meshed STSG 0f 1:3 expansion ratio, used STSG with variable thickness (0.012 in to O-016 in) and Alexander [1] in his technique (meshed allograft overlaying meshed STSG) used a variable STSG thickness ranged from 0.010 in to 0.014 inch which could make some bias) in contrast to the present study we fixed the thickness (0.014 in). That is agree with Sakamoto et al., [14] who emphasized that the variability in size and shape of used skin grafts made them unsuitable for the accurate evaluation of the wound healing process.

Lin et al., [13] documented the time of complete healing around the 7 th day post grafting which go along with our results in the present study as we registered the time of complete healing ranged (712) days mean \pm SD $9.3 \pm 1.5$ in group 1 and (710) days mean \pm SD $7.7 \pm 1.2$ in group 2 with a significant $p$-value $0.014 *$ when comparing group 1 VS. 2.

The present study revealed that the percentage of graft take did not show any statically difference between the 2 groups. In a contrast to the study of Lin in 1985 [8] and Mohammadi et al., [10] who documented the advantages of AM in minimizing hemorrhage, contamination, slipping and mechanical disruption of the meshed skin during the changing of dressings which affects the percentage of the take of the graft.

In AM groups (2) we used skin staples at the edges of the AM to fix the graft that agreed with Mohammadi \& Johari [16] who had a significant decrease in the number of the used staples and the missed staples as foreign bodies commonly noticed when patients do X-rays over grafted regions.

Loeffelbein et al., [17] evaluated the epithelialization of the donor sites of skin grafts after coverage with AM. The epithelial thickness revealed a significantly broader epithelium in the AM group on day $7(p<0.001)$. In our series the maturation of the epithelium (Table 3) showed a significant $p$-value in the $10^{\text {th }}$ day $0.006^{*}$ when comparing group 1 VS. 2.

To the best of our knowledge the present study is the first to document the transformation of the blood vessels from newly formed capillaries to mature ones at the $5^{\text {th }}$ day with significant $p$-value $\left(0.006^{*}\right)$ in the $10^{\text {th }}$ day when comparing the AM groups (2) vs the control group 1. Obviously, the mature blood vessels showed significant $p$-values when the $5^{\text {th }}$ day was compared with the other days in both groups as shown in (Table 4).

The collagen synthesis and its transformation from fibrils into bundles in the current study showed no significance between the 2 groups but the significance had been showed when the $5^{\text {th }}$ day compared with the other days. Further investigation is needed to detect which type of collagen deposited during the healing process, collagen type 3 and or type 1 .

Gonzalez et al., [18] described the proliferative phase of wound healing by the presence of (lymphocytes and fibroblast). In the current study the (lymphocytes and fibroblast) cells started to appear in group (2) with the use of AM coverage in the $5^{\text {th }}$ with a statistically significant $p$-value: $0.003^{*}$ when compared with the control group which indicated that AM accelerated the initiation of the proliferative phase of wound healing.

The Patient and Observer Scar Assessment Scale (POSAS) was designed to evaluate various types of scar subjectively. It provides both the observers' and the patient's insights and it is easy to use, proving to be more advantageous than other tools. It was used to evaluate burn scars and linear surgical scars, which showed reliable and valid results for scar evaluation $[\mathbf{1 9 , 2 0 ]}$.

In the current study, it was shown that group (2) treated with AM achieved an improvement in all items of both POSAS and OSAS score when the results compared with the control group (1).

Commonly it is normal when that the patients consider their scars more unpleasant than the observer does as stated by Bianchi et al., [21] that agreed with the results of the recent study as the total score of PSAS showed significant $p$-value: $0.001^{*}$ and the total score of the OSAS shoed $p$ value: $0.002 *$.

In literature, pain and itching are of the most disturbing issues for a patient. Willebrand in 2004 [22] reported to be present in the rehabilitation phase as high as $87 \%$ in adults and $100 \%$ of chil- 
dren. PSAS score reported a great improvement in this item with $p$-value: $0.003^{*}$.

All items of POSAS reported a great improvement in all the items with statistically significance when comparing group $1 \mathrm{VS}$. 2. That indicated the better cosmetic outcome of the use of the AM in covering meshed STSG which agreed with the result of Mohammadi et al., [23] who used AM dressing over meshed skin grafts with an expansion ratio of $(1: 1.5)$ and assessed the aesthetic out come with Vancouver scar scale.

\section{Conclusion:}

Amniotic membrane, a biological dressing for meshed STSG, enhanced maturation of epithelium, increased the transformation of the newly formed capillaries into mature ones, accelerated the initiation of the proliferative phase of wound healing and promoted the re-epithelialization of the interstices of the meshed graft. The type of collagen formed should need further investigation to assess the remolding phase of the healing process of the meshed STSG. Amniotic membrane had led to a better cosmetic outcome after the use of the AM in covering meshed STSG.

\section{REFERENCES}

1- Alexander J.W., MacMillan B.G., Law E. and Kittur D.S.: Treatment of severe burns with widely meshed skin autograft and meshed skin allograft overlay. The Journal of Trauma, Jun., 21 (6): 433-8, 1981.

2- Smith P.D., Polo M., Soler P.M., McClintock J.S., Maggi S.P., Kim Y.J., Ko F. and Robson M.C.: Efficacy of growth factors in the accelerated closure of interstices in explanted meshed human skin grafts. The Journal of burn care \& rehabilitation, Jan. 1, 21 (1): 5-9, 2000.

3- Nikkhah D., Booth S., Tay S., Gilbert P. and Dheansa B.: Comparing outcomes of sheet grafting with $1: 1$ mesh grafting in patients with thermal burns: A randomized trial. Burns, Mar. 1, 41 (2): 257-64, 2015.

4- Chu C.S., Matylevitch N.P., McManus A.T., Goodwin C.W. and Pruitt Jr. B.A.: Accelerated healing with a mesh autograft/allodermal composite skin graft treated with silver nylon dressings with and without direct current in rats. Journal of Trauma and Acute Care Surgery, Jul. 1, 49 (1): 115-25, 2000.

5- Parolini O., Soncini M., Evangelista M. and Schmidt D.: Amniotic membrane and amniotic fluid-derived cells: potential tools for regenerative medicine? 275-291, 2009.

6- Niknejad H., Peirovi H., Jorjani M., Ahmadiani A., Ghanavi J. and Seifalian A.M.: Properties of the amniotic membrane for potential use in tissue engineering. Eur. Cells Mater., 15: 88-99, 2008.

7- Halim A.S., Khoo T.L. and Yussof S.J.: Biologic and synthetic skin substitutes: An overview. Indian Journal of Plastic Surgery: Official publication of the Association of Plastic Surgeons of India, Sep., 43 (Suppl): S23, 2010.
8- Sheikh E.S., Sheikh E.S. and Fetterolf D.E.: Use of dehydrated human amniotic membrane allografts to promote healing in patients with refractory non healing wounds. International Wound Journal, Dec., 11 (6): 7117, 2014.

9- Mohammadi A.A., Sabet B., Riazi H., Tavakko-lian A.R., Mohammadi M.K. and Iranpak S.: Human amniotic membrane dressing: An excellent method for outpatient management of burn wounds. Iranian Journal of Medical Sciences, May 12, 34 (1): 61-4, 2015.

10- Dua H.S., Gomes J.A., King A.J. and Maharajan V.S.: The amniotic membrane in ophthalmology. Survey of ophthalmology, Jan. 1, 49 (1): 51-77, 2004.

11- Tanner J.C., Vandeput J.A. and Olley J.F.: The mesh skin graft. Plast. Reconstr. Surg., Sep., 34 (3): 287-92, 1964.

12- Maggi S.P., Soler P.M., Smith P.D., Hill D.P., Ko F. and Robson M.C.: The efficacy of 5\% Sulfamylon ${ }^{\circledR}$ solution for the treatment of contaminated explanted human meshed skin grafts 1. Burns, May 1, 25 (3): 237-41, 1999.

13- Lin S.D., Lai C.S., Hou M.F. and Yang C.C.: Amnion overlay meshed skin autograft. Burns, Jun. 1, 11 (5): 3748, 1985.

14- Sakamoto M., Morimoto N., Inoie M., Takahagi M., Ogino S., Jinno C. and Suzuki S.: Cultured Human Epidermis Combined With Meshed Skin Autografts Accelerates Epithelialization and Granulation Tissue Formation in a Rat Model. Annals of Plastic Surgery, Jun., 78 (6): 651, 2017.

15- Mohammadi A.A., Jafari S.M., Kiasat M., Tavakkolian A.R., Imani M.T., Ayaz M. and Tolide-ie H.R.: Effect of fresh human amniotic membrane dressing on graft take in patients with chronic burn wounds compared with conventional methods. Burns, Mar 1, 39 (2): 349-53, 2013.

16- Mohammadi A. and Johari H.G.: Amniotic membrane: A skin graft fixator convenient for both patient and surgeon. Burns, Nov. 1, 34 (7): 1051-2, 2008.

17- Loeffelbein D.J., Rohleder N.H., Eddicks M., Baumann C.M., Stoeckelhuber M., Wolff K.D., Drecoll E., Steinstraesser L., Hennerbichler S. and Kesting M.R.: Evaluation of human amniotic membrane as a wound dressing for split-thickness skin-graft donor sites. Bio. Med. Research International, 2014.

18- Gonzalez A.C., Costa T.F., Andrade Z.D. and Medrado A.R.: Wound healing-A literature review. Anais brasileiros de dermatologia, Oct., 91 (5): 614-20, 2016.

19- Draaijers L.J., Tempelman F.R., Botman Y.A., Tuinebreijer W.E., Middelkoop E., Kreis R.W. and Van Zuijlen P.P.: The patient and observer scar assessment scale: A reliable and feasible tool for scar evaluation. Plastic and Reconstructive Surgery, Jun. 1,113 (7): 1960-5, 2004.

20- Van De Kar A.L., Corion L.U., Smeulders M.J., Draaijers L.J., Van Der Horst C.M. and Van Zuijlen P.P.: Reliable and feasible evaluation of linear scars by the Patient and Observer Scar Assessment Scale. Plastic and reconstructive surgery, Aug. 1, 116 (2): 514-22, 2005.

21- Bianchi F.A., Roccia F., Fiorini P. and Berrone S.: Use of Patient and Observer Scar Assessment Scale for evaluation of facial scars treated with self-drying silicone gel. Journal of Craniofacial Surgery, May 1, 21 (3): 719-23, 2010. 